\title{
Do dois ao três, ou A reprodução da burrice paulista
}

\author{
[ From two to three, or The reproduction of the Paulista stupidity
}

\section{Victor Santos Vigneron ${ }^{\mathrm{I}}$}

RESUMO $\cdot O$ objetivo deste artigo é analisar o projeto de adaptação cinematográfica do romance Amar, verbo intransitivo, produzido por Paulo Emílio Salles Gomes no final dos anos I960. Propõe-se relacionar as escolhas formais e temáticas feitas pelo autor com outros aspectos significativos de sua trajetória. Espera-se, dessa maneira, recompor as posições estéticas e teóricas articuladas diante do regime militar. Nesse sentido, o recurso de Salles Gomes à ficção parece constituir um lance decisivo numa estratégia mais ampla de reconfiguração intelectual. • PALAVRASCHAVE - Burguesia; burrice; masculinidade.

\begin{abstract}
- ABSTRACT - This essay aims to analyze the film adaptation project of the novel "Amar, verbo intransitive", produced by Paulo Emílio Salles Gomes in the end of the I96os. It is proposed connecting the formal and thematic choices made by the author with other meaningful aspects of his trajectory. Thus, it is expected recomposing the aesthetic and theoretical positions developed in the face of the military dictatorship. In this sense, Salles Gomes' resource to fiction seems to form a central move in a broader strategy of intellectual reconfiguration. - KEYWORDS Bourgeoisie; stupidity; masculinity.
\end{abstract}

Recebido em 24 de maio de $202 I$

Aprovado em I3 de setembro de $202 \mathrm{I}$

VIGNERON, Victor Santos. Do dois ao três, ou A reprodução da burrice paulista. Revista do Instituto de Estudos Brasileiros, Brasil, n. 80, p. 68-87, dez. 202I.

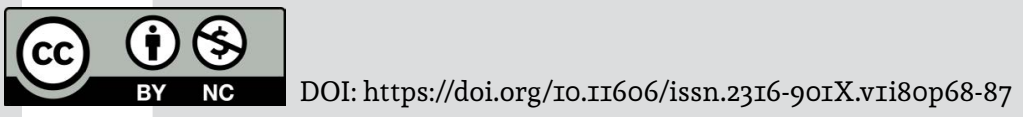

I Universidade de São Paulo (USP, São Paulo, SP, Brasil). 


\section{Conjugação}

Entre I968 e I969, Paulo Emílio Salles Gomes dedicou-se a adaptar para o cinema o romance Amar, verbo intransitivo, publicado originalmente em I927. Desse esforço, resultou um material, hoje depositado na Cinemateca Brasileira, composto de dois roteiros (PI OII7 - GOMES, I969a; e OII7.0I - GOMES, I969b) e uma pequena correspondência com Odete Lara (CA 0585 - GOMES, I968; e CP I533 - Lara, I968). As duas versões possuem diferenças significativas na maneira como abordam o livro de Mário de Andrade, fato já estudado por Carla Kinzo (20I4). Assumo como estabelecida, nas suas linhas gerais, a comparação com o romance de referência e centro-me nas continuidades e rupturas em relação a outros escritos do próprio Salles Gomes, com o fito de acrescentar alguns nexos explicativos ao panorama delineado pela pesquisadora.

A produção ficcional é uma linha irregular que se estende por toda a trajetória de Salles Gomes. Sua entrada na vida pública, em meados dos anos I930, foi acompanhada por uma floração de textos poéticos e teatrais, interrompida no início da década seguinte. Essa mudança coincide com o retorno de Salles Gomes a São Paulo e com sua participação na revista Clima, onde publicou suas primeiras críticas de cinema. A passagem ao registro "sério" (crítica), ainda que num polo fraco (cinema), converge com a análise proposta por Heloisa Pontes (I998, p. I23-I39) a respeito da divisão do trabalho na revista. $\mathrm{O}$ apoio logístico-afetivo ${ }^{2}$ e a produção ficcional (Gilda de Mello e Souza, Lygia Fagundes Telles etc.), posições ocupadas pelas mulheres, contrastam com a autodefinição dos "climáticos" (Antonio Candido de Mello e Souza, Décio de Almeida Prado, Lourival Gomes Machado, Ruy Coelho etc.) em torno da crítica. No caso de Salles Gomes, o atributo da seriedade, construído através da profissionalização da crítica cinematográfica (cujo polo fraco seria Guilherme de Almeida), teria como contrapartida o recalque da produção ficcional

2 É importante acrescentar às trajetórias indicadas por Pontes a figura de Sônia Veloso Borges, primeira esposa de Salles Gomes. Ela foi revisora de Jean Vigo, publicado por seu companheiro em I957, secretariou-o informalmente na organização do I Festival Internacional de Cinema do Brasil, em I954, e traduziu a História mundial do cinema, de Georges Sadoul, publicada em I963 com prefácio de Salles Gomes. 
e de temas considerados menores, fato experimentado na censura de Clima ao seu artigo sobre o palhaço Piolim (GOMES, I986a)³.

A hipótese do recalque da escrita ficcional como mudança necessária à construção do que viria a ser chamado "destino" permite, ainda, iluminar outra passagem da trajetória intelectual de Salles Gomes. Pois ele reata com a ficção em I962, ao escrever o roteiro Dina do cavalo branco (PI oII6-GOMES, I962a; PI oII6.oI - GOMES, I982b; e PI oII6.02 - GOMES, I96-a). De Clima a Dina, teve lugar a construção de uma posição intelectual que combinava uma metodologia de análise com uma estratégia de atuação no espaço público, articulada em torno de lugares tão "climáticos" quanto a Cinemateca Brasileira e o Suplemento Literário do jornal O Estado de S. Paulo. Foi ao cabo dessa construção da carreira que a ficção tornou ao horizonte dos possíveis, ainda que sua necessidade se inscreva na encruzilhada vivida no início dos anos I960.

Esse momento era expresso com maldisfarçada frustração por parte do crítico diante da mediocridade do seu campo de atuação, evidenciada pela tímida posição do Estado e da elite política em relação ao problema cinematográfico. O otimismo palmilhante de sua tese Uma situação colonial? (GOMES, 20I6, p. 47-54) - publicada meses depois da inauguração de Brasília, momento em que o autor alimentava expectativas em relação à política cinematográfica do recém-eleito Jânio Quadros - não sobreviveria às sucessivas derrotas que começaram a apontar no horizonte antes mesmo do golpe militar de I964. A escrita de Dina do cavalo branco se inscreve, portanto, no contexto do sucesso truncado de seu autor, reconhecido pelo campo, mas impotente para além de suas exíguas fronteiras. Outra face desse estranho ápice foi o diálogo desencontrado com o Cinema Novo. Afinal, o roteiro ocupa um lugar de destaque na relação tumultuada de Salles Gomes e Glauber Rocha (PINTO, 2008, p. 87-93), aparecendo num momento de obstrução da centralidade do crítico paulista no interior de um campo atravessado pela emergência de novos atores. Ainda que amparada pelo cinema - trata-se de um roteiro -, Dina marcou um retorno à literatura, de modo a desempenhar um papel significativo na recalibragem do destino de seu autor. Em suma, a liberação da experiência ficcional era possível após a consolidação da carreira e necessária diante de uma nova ameaça de marginalização.

A experiência literária de Salles Gomes seria aprofundada a partir de então. Ao longo dos anos I960, ele produziu quatro roteiros: Dina do cavalo branco (I962), roteiro original, não filmado; Capitu (I966; GOMES; TELLES, 2008), adaptação de Dom Casmurro (I899, Machado de Assis), em parceria com Lygia Fagundes Telles e com colaboração de Paulo César Saraceni, filmado com o título Capitu (I968, dir. Paulo César Saraceni); Em memória de Helena (I967; PI 0268 - GOMES, I96-b; e PI 0268.0I - GOMES, I96-c), adaptação bastante livre de Minha vida de menina (I942, Helena Morley), com colaboração de David Neves, filmado com o título Memória de Helena (I969, dir. David Neves); Amar, verbo intransitivo (I968-69), adaptação do romance homônimo de Mário de Andrade (I927), não filmado. Nos anos I970, a produção

3 Esse comentário não dá conta da atuação de Salles Gomes no início dos anos I940. Além do trabalho de Heloisa Pontes (1998), o período foi analisado por José Inacio de Melo Souza (2002), Adilson Mendes (2013) e Rafael Zanatto (20I8). As considerações feitas abaixo a respeito da trajetória do crítico nas décadas seguintes se baseiam largamente nestes autores. 
ficcional de Salles Gomes adquiriu autonomia em relação ao cinema, renunciando à forma roteiro. $\mathrm{O}$ lance mais conhecido dessa passagem são as novelas Três mulheres de três PPPês, escritas em I973 e publicadas em I977 (GOMES, 20I5). Outros materiais também foram produzidos nesse momento, entre os quais se destaca um extenso manuscrito inacabado, elaborado entre I973 e I976, conhecido hoje pelo título atribuído Cemitério (GOMES, 2007).

Considerando esses parâmetros básicos da trajetória ficcional de Salles Gomes, o propósito deste comentário é analisar Amar, verbo intransitivo como espaço de cristalização de algumas tendências e impasses. "Etapa" é uma palavra que não se presta bem a descrever a posição do roteiro, pois a reconfiguração que vai se processando paulatinamente traz evidências de amadurecimento, mas também se compõe de dúvidas e descartes. Seguindo uma sugestão de Carla Kinzo (20I4), talvez se possa falar numa "conjugação" de problemáticas, que tomou forma na própria hesitação do material que ora passo a analisar.

\section{Parâmetros para Amar}

Diferentemente dos demais roteiros, Amar, verbo intransitivo recebeu dois tratamentos, sendo impossível estabelecer uma relação de precedência entre suas versões. Nos outros casos é comum a ocorrência de supressões, substituições e acréscimos na passagem do manuscrito à versão datilografada, ao passo que a versão I (PI oII7 - GOMES, I969a) e a versão II (PI oII7.OI - GOMES, I969b) de Amar, verbo intransitivo não marcam diferentes estágios de uma mesma abordagem, mas maneiras distintas de se relacionar com o livro de Mário de Andrade. Em termos cronológicos, é provável que a versão II seja anterior à versão I ${ }^{4}$. A versão II é toda manuscrita, o que sugere um tratamento anterior, a considerar o modo típico de produção de Salles Gomes; a versão I, por sua vez, é uma cópia xerográfica de um original datilografado, acompanhada de um resumo. Além disso, em carta enviada a Odete Lara em março de I968 (CA 0585-GOMES, I968a), antes da elaboração das duas versões, Salles Gomes envia uma sinopse que se aproxima da abordagem presente na versão II. Não fica claro, à luz das poucas informações trazidas na correspondência com Odete Lara, o que motiva o autor a elaborar essas versões alternativas. Para refletir sobre essa hesitação e sobre o sentido das variações presentes nos roteiros é necessário recorrer a alguns parâmetros fornecidos pela trajetória geral da documentação de Salles Gomes nos anos I960.

Em que pesem as precauções analíticas referentes à trajetória de constituição de um arquivo pessoal (HEYEMANN, I997), é possível observar uma transformação no padrão da documentação de Salles Gomes ao longo do tempo. Especialmente a partir de I963, registra-se uma redução acentuada nas publicações do crítico no Suplemento Literário e na revista Visão, fato que não chegou a ser compensado pelo início de sua colaboração no semanário Brasil, urgente. Paralelamente, observa-se a ampliação da escrita associada à posição de Salles Gomes na Cinemateca Brasileira e, depois, na

4 Fica mantida aqui, no entanto, a numeração utilizada por Kinzo (2014, p. 95-97). 
Universidade de Brasília (UnB) e na Universidade de São Paulo (USP). Há, portanto, uma restrição da presença do intelectual no espaço público mediado pela imprensa.

O golpe militar de 1964 aprofundou essa tendência. Marcado pelos órgãos de informação do Estado desde sua prisão na repressão que se seguiu à Revolta Comunista, em 1935, Salles Gomes teve sua atuação cerceada pela ditadura 5 . Em I965, participou da demissão coletiva de docentes da UnB; em I968, teve sua coluna no jornal A Gazeta descontinuada, o que voltou a acontecer em I973, no Jornal da Tarde. Restou-lhe então a possibilidade de publicar em veículos de menor circulação, como a imprensa alternativa (Argumento, Movimento, Opinião). A isso se soma uma ampliação das tarefas docentes, com a consequente conversão da produção escrita para documentos de ordem burocrático-didática (ofícios, aulas, correções etc.). Inclusive depois da demissão da UnB, pois o crítico aprofundaria sua participação na USP a partir de I966, sobretudo com sua passagem da Faculdade de Filosofia, Ciências e Letras (FFCL/USP) para a recém-criada Escola de Comunicações Culturais (futura Escola de Comunicações e Artes - ECA/USP), que implementaria um curso de Cinema $^{6}$. Essa atuação seria pontuada pela perseguição política no interior da USP, que conheceria um ápice com a ameaça de desligamento em I974.

O ano de I966 marca a sedimentação de certos parâmetros que estariam vigentes quando da produção de Amar, verbo intransitivo. Foi nessa época que Salles Gomes deu início a uma produção mais sistemática de roteiros, a partir de Capitu, e produziu importantes materiais didáticos. Por ocasião do curso O Cangaço na Realidade e na Cultura Brasileira, organizado pelo Instituto de Estudos Brasileiros da USP, o crítico sistematizou discussões ligadas à produção cinematográfica da primeira metade dos anos I960 no curso O Universo Fílmico do Cangaço (PI 0486 - GOMES, I966a; 0486.0I - GOMES, I966b; 0486.2 - GOMES, I966c; e 0486.03-GOMES, I966d). Por essa época, as tarefas disciplinares também deixaram sua marca na reflexão historiográfica do autor. Nesse sentido, o pesquisador Rafael Zanatto (202I) tem sublinhado a vinculação entre o material do curso Os Filmes na Cidade e a produção do "Panorama do cinema brasileiro" (GOMES, 20I6, p. II9-I66), publicado em I966 no álbum 70 anos de cinema brasileiro. Esse ensaio dá início a um processo de sistematização historiográfica por parte de Salles Gomes (ZANATTO, 2018, p. 434-474), movimento que inclui uma aproximação com a comédia musical e com o gênero do cangaço, presentes nos cursos de I966. Sistematização historiográfica e sistematização ficcional correm, portanto, em paralelo. Mais que isso, trata-se de movimentos entrelaçados, como indica Capitu (GOMES; TELLES, 2008).

Esse roteiro é parte de uma aproximação mais ampla do autor com a obra de

5 A atuação política de Salles Gomes em geral é marcada, inclusive por ele próprio, até o ano de I945. Outro recalque, aqui deslocado para o período final de Clima. Acerca das mediações entre política e produção do saber num âmbito não de todo indiferente a Salles Gomes, cf. Lidiane Rodrigues (20II).

6 A análise de Pontes (I998, p. 20I-2II) fecha-se, no caso de Salles Gomes, com seu processo tardio de institucionalização universitária. Caminhos cruzados, ainda uma vez, do "grupo Clima”, dado o abrigo institucional fornecido ao crítico pela cátedra ocupada por Antonio Candido na FFCL/USP e, mais tarde, na orientação de sua tese de doutorado por Gilda de Mello e Souza. Esse processo foi de par com a oficialização do ensino de cinema no país, que recrutou seus primeiros quadros no campo da crítica e da produção, diferentemente do que ocorreu em outros lugares. 
Machado de Assis (MASSI, 2008). Bem antes da sistematização ficcional (Capitu) e universitária (o curso Machado de Assis e o Cinema, realizado na USP em I974), o escritor esteve no centro de uma discussão sobre a natureza das relações entre cinema e literatura no artigo “O narrador e a câmera” (Suplemento Literário, I958; GOMES, I98I, v. I, p. 4I6-4I9). No confronto com a ideia de uma "intuição cinematográfica" da parte de Machado de Assis, proposta pelo crítico Raymundo Magalhães Jr., Salles Gomes retoma um conhecido artigo de Serguei Eisenstein, “Dickens, Griffith e nós” (2002, p. I76-224), com o objetivo de indicar a ascendência da literatura sobre a linguagem do cinema. Mas o entrelaçamento da produção ficcional com a reflexão específica sobre Machado de Assis se define apenas em I966, ano em que se espelham a visada proposta em Capitu para o Segundo Império e o já mencionado curso Os Filmes na Cidade, em que o escritor aparece como nexo importante para a compreensão do tecido cultural que se prolongaria na chanchada.

Contudo, a própria ideia de entrelaçamento talvez seja insuficiente para delinear o lugar da ficção na obra de Salles Gomes. Afinal, no início da década de I960, o autor empreende uma deriva ficcional em plena atividade crítica, sobretudo no semanário Brasil, Urgente (PINTO, 2008, p. I22-I36). O crítico parece consciente desse fato, uma vez que chega a comentar, em carta a Michelle Starling datada de abril de I963 (CA 0430 - GOMES, I963), o gosto particular da liberdade proporcionada pelos artigos escritos para aquele jornal. Posteriormente, em correspondência enviada a Yolanda Leite em janeiro de I965 (CA 0444- GOMES, I965), ressalta em termos semelhantes a importância do artigo "Um discípulo de Oswald em I935" (GOMES, I98I, v. 2, p. 440-446)7. A porosidade entre registro ficcional e "seriedade" crítica ou acadêmica voltaria a ser notada por Alfredo Bosi (2003, p. 243-254), em sua arguição à tese de doutorado de Salles Gomes, em I972. Nessa ocasião, Bosi chamaria a atenção para a longa digressão inicial, dedicada à formação da Zona da Mata mineira, enfatizando seu valor literário e sua peculiar centralidade numa tese sobre os filmes silenciosos de Humberto Mauro.

Talvez as piscadelas lançadas ao público, as anedotas e digressões que aparecem nos textos de Salles Gomes no início dos anos I960, constituam uma resposta à sua "perda de atualidade" em relação ao cinema brasileiro. Mais que uma compensação por faltar ao encontro, no entanto, essas modalidades expressivas parecem apontar para algo novo, ao estabelecer uma relação com o público que não era mediada pelo cinema. Nesse contexto, a liberação do registro ficcional era acompanhada pelo recurso constante às memórias do autor, que desempenham um papel de destaque nos artigos da época. A tendência à ficção, portanto, estabelece analogia com o deslocamento memorialístico, ainda que sob a licença poética do disparate das associações ${ }^{8}$. Importante lembrar a essa altura que o deslocamento temporal era

7 O fato de Oswald de Andrade ser um marcador temático dessa passagem à ficção não parece secundário. Como se verá, o escritor modernista desempenha um papel de destaque em Amar, verbo intransitivo.

8 Dois exemplos: em “Variação de enterrado vivo”, de I963 (GOMES, I986b), o autor evoca a experiência da fuga do Presídio do Paraíso, em I937, a propósito de um filme de terror; em "Um mundo de ficções”, de I960 (GOMES, 20I6, p. 55-6I), lembra uma visita a Washington Luís no exílio parisiense para tratar das ilusões em torno do cinema brasileiro. 
uma estratégia então adotada pelo próprio Cinema Novo, como observou Jean-Claude Bernardet (2007, p. I04-I09) a respeito de filmes como Vidas secas (I963, direção de Nelson Pereira dos Santos) e Deus e o diabo na terra do sol (I964, direção de Glauber Rocha). Da parte de Salles Gomes, esse recurso seria incorporado na elaboração dos roteiros, como se vê em: Dina do cavalo branco, pelo uso do flashback como moldura do enredo; Em memória de Helena, em que a inserção de um arquivo audiovisual intradiegético funciona como suporte para o exercício da memória; Capitu, pela aproximação entre o Segundo Império e o presente, sugerida explicitamente por Paulo César Saraceni (CP I730 - SARACENI, s. d.).

A adaptação dirigida por Saraceni, no entanto, não foi bem recebida por Salles Gomes. Ao lado de Vidas secas, Capitu receberia uma menção negativa numa conferência realizada no fim dos anos I960, documentada no material "Roteiro p/ Unesco" (PI 05I6 - GOMES, s. d.). Em ambos os casos, tratar-se-ia de adaptações muito presas à letra (Capitu) ou ao espírito (Vidas secas) do romance de referência, o que configuraria uma forma limitada de respeito ao original. Ainda de acordo com o "Roteiro", uma vinculação crítica com a obra favoreceria as abordagens de Glauber Rocha (em sua relação com Euclydes da Cunha e João Guimarães Rosa) e de Macunaíma (I969, direção de Joaquim Pedro de Andrade)9. É importante lembrar que o "Roteiro p/ Unesco" foi elaborado na mesma época das versões de Amar, verbo intransitivo. Com isso, pretendo sugerir que a reflexão construída ao longo dos anos I960 em torno da adaptação cinematográfica de obras literárias, presente em críticas e roteiros, seria sistematizada nos dois materiais, o que talvez ajude a explicar as hesitações dos roteiros de I968-1969, trabalhados em duas direções. Considerando essas mudanças pelas quais passava a obra de Salles Gomes ao longo dos anos I960, talvez seja possível aferir com mais precisão as escolhas formais e temáticas de Amar, verbo intransitivo, elencadas a seguir.

\section{SINOPSE TEMÁTICO-FORMAL DOS ROTEIROS RESTRIÇÃO DO ESCOPO TEMÁTICO}

Nas duas versões, Amar, verbo intransitivo restringe seu universo social à burguesia paulista ${ }^{\mathrm{Io}}$. Essa delimitação aparece igualmente em dois projetos, sem data, intitulados "Roteiro p/ mim" (PI oII5-GOMES, s. d.) e "Projeto de comédia dramática sofisticada para o cinema paulista” (PI 0207-GOMES,I96-d). Nos roteiros de I968-I969, o enredo encerra-se no problema da "iniciação sexual sã" como arena em que se joga o futuro de uma classe, analisada através de um caso representativo.

9 O segundo parâmetro para a avaliação dessas adaptações é o ensaio "O Diário de um pároco de aldeia e a estilística de Robert Bresson”, publicado por André Bazin nos Cahiers du cinema em I95I (BAZIN, 20I4, p. I37-I54).

Io Carlos Augusto Calil (2007a; 2007b) se refere ao ressentimento de Salles Gomes em relação à elite paulista, manifesto em suas obras dos anos I970. "Ressentimento" talvez seja um conceito pouco feliz para definir a trajetória criadora (e não reativa) do autor, embora estabeleça o arco de uma construção ficcional que deita raízes na experiência política dos anos I930 e I940. 
Evidentemente, a personagem Elza (a Fräulein) não pertence ao mesmo núcleo social da família de Felisberto Souza Costa, na qual ingressa na condição de prestadora serviço. É justamente a ameaça do rompimento dessa condição (com a confusão entre educação sexual e educação sentimental do menino Carlos) que move o enredo. O desfecho, através da "normalização" das relações, termina por referendar o enquadramento inicial, delimitando as personagens que não pertencem à burguesia à condição de subordinados (além de Elza, os demais trabalhadores da família, como a negra Marina e o empregado japonês) ou de estranhos membros, em ascensão (Mme. Pommery, prostituta enterrada no Cemitério da Consolação às expensas do general Nepomuceno) ${ }^{\mathrm{II}}$ ou em decadência (o futurista Raul Morais, além de Oswald, Menotti e Guilherme). Essa estrutura amarrada em uma classe contrasta com Dina do cavalo branco, em que a figura do povo ainda era articulada em torno de um universo próprio de pescadores e operários, em choque com o mundo grã-fino ${ }^{\mathrm{I} 2}$.

Essa restrição seria intensificada nos anos I970 em Três mulheres de três PPPês e Cemitério, cujos enredos transitam em torno da burguesia paulista, seus lugares (Alto de Pinheiros, Pacaembu etc.), seus objetos, seus temas. Assim, essa atmosfera conferiu certa coesão temática à produção ficcional de Salles Gomes a partir de Amar, verbo intransitivo. Mas vale destacar que a definição desse tema não se restringe à ficção do autor, uma vez que essa tendência dialoga com sua atuação em contextos mais "sérios". Ao cabo de sua conhecida tese "Cinema: trajetória no subdesenvolvimento", de I973, o crítico define como objeto/interlocutor a "aristocracia do nada, uma entidade em suma muito mais subdesenvolvida do que o cinema brasileiro que desertou" (GOMES, 20I6, p. 205). Essa definição ganha um contorno mais claro no filme Tem coca cola no vatapá (I975, direção de Pedro Farkas e Rogério Corrêa), em que o interlocutor elitizado toma a forma dos alunos da ECA/USP, apresentados em debate com o próprio Salles Gomes, autor dos diálogos do filme.

\section{Adensamento descritivo: índices}

A propósito de Zulmira Ribeiro Tavares e seu romance $O$ nome do bispo (I985), Roberto Schwarz (2004) apontou para o que se poderia chamar de "deriva etnográfica" da autora, que se demora em descrever minuciosamente diversos aspectos da burguesia paulista, num recorte muito semelhante ao dos livros de Salles Gomes. Importante lembrar que as relações entre Salles Gomes e Tavares são intensas, sendo ela a responsável pela publicação de Três mulheres de três PPPês pela editora Perspectiva. Importa registrar aqui que Amar, verbo intransitivo marca não apenas uma restrição do escopo temático, mas também um adensamento descritivo análogo àquele presente nos livros de Tavares, fato que se aprofunda em Três mulheres. É interessante observar que os trechos suprimidos do manuscrito dessa obra, comentados por

II Madame Pommery é a personagem-título de um livro de Hilário Tácito publicado em I9I9, que trata justamente da vinculação da prostituição com a elite do café em São Paulo.

I2 Nos anos I960, Jean-Claude Bernardet (2007, p. 52-57) analisou a ocorrência desse modelo num âmbito muito próximo de Dina, o filme A grande feira (I96I, direção de Roberto Pires). 
Carlos Augusto Calil (2007b) e Roberto Schwarz (2007), dão conta não apenas de uma "descrição densa" dos costumes da elite, mas de uma verdadeira obsessão descritiva ${ }^{\mathrm{I} 3}$. Nos roteiros de I968-I969, essa posição se manifesta na minuciosa descrição dos aspectos materiais do filme a ser produzido: das indicações ao longo do roteiro acerca de documentos presentes na Cinemateca relativos ao período narrado ${ }^{\mathrm{I}}$ à preocupação com a escolha de automóveis e trens, presentes numa nota aposta ao fim da versão II.

Esse aumento quantitativo engendra uma mudança qualitativa, revelada nas diferenças formais em torno da encenação que se evidenciam, mais uma vez, na comparação com Dina. No roteiro de I962, os objetos e instituições desempenhavam um papel de signos (como na associação entre o uísque importado e os grã-finos ou na vinculação do polo operário com a Petrobras), de modo a adquirir autonomia. Em Amar, os objetos são descritos com maior perícia, mas perdem sua autonomia, uma vez que se tornam antes índices parciais de classe. Só significam em constelação com outros. Um exemplo desse fato é o piano, objeto das lições de uma das filhas de Felisberto: ele não possui autonomia, mas sua presença remete a uma rede de referências irônicas à vida burguesa, seja numa chave involuntária (o desejo da mãe de que a menina se torne uma Guiomar Novaes), seja explicitamente (a crítica de Oswald à presença de Chopin num romance-roteiro futurista). É interessante notar como alguns desses objetos reaparecem em outras produções de Salles Gomes da época. No caso do piano (e de Guiomar Novaes), esse tema assume novamente a condição de índice para compreensão da mentalidade burguesa na tese subsidiária de doutorado escrita pelo autor no início dos anos I970 (PI 0840 - GOMES,I97-). Outra figura que aparece em mais de uma ocasião no roteiro de Amar, verbo intransitivo é o boi zebu, que possui, como se verá, uma possível significação suplementar ${ }^{15}$.

Esse adensamento descritivo acompanharia também as reflexões estritamente cinematográficas de Salles Gomes, como notou Rafael Zanatto (20I8, p. 490-5I2) a respeito da conferência "O cinema brasileiro na década de trinta", de I973 (PI 0296 GOMES, I973). E se Zulmira Ribeiro Tavares é uma das interlocutoras privilegiadas nesse sentido, é igualmente fundamental o diálogo com a produção de Maria Rita Galvão. Se no próprio título de sua Crônica do cinema paulistano (GALVÃO, I975) aparece a referência ao gênero que marcara a produção crítica de Salles Gomes no início dos anos I960, é interessante notar o intercâmbio efetivo entre os dois intelectuais ${ }^{16}$. Ainda que a relação orientador-orientanda sugira que o diálogo privilegiou determinado sentido, é interessante observar a presença de considerações retiradas de Crônica do cinema paulistano em materiais de Salles Gomes, como no

I3 O caráter maníaco da descrição, em Salles Gomes, talvez seja um traço a diferenciá-lo de Tavares.

I4 Como o filme True heart Susie (I9I9, direção de David Griffith) e edições da revista A scena muda.

I5 $\mathrm{O}$ zebu, tema que aparece no romance de referência e é mencionado por Mário de Andrade em outras ocasiões, num momento de amplos debates a respeito da conveniência de sua importação, é um dos elementos centrais de outro livro de Zulmira Ribeiro Tavares, Café pequeno (I995).

I6 Salles Gomes orientou Galvão na elaboração de sua dissertação de mestrado, publicada como Crônica do cinema paulistano (I975), defendida em I969, e em sua tese de doutorado, publicada parcialmente como Burguesia e cinema (I98I), defendida em I975. 
roteiro "Possibilidade de um filme de longa-metragem em torno do cinema paulista de I934 a I949” (PI oI73 - GOMES, s. d.; e PI o6I4 - GOMES, s. d.). Em suma, o cuidado com os detalhes dá corpo à construção de uma atmosfera social, em que a própria linguagem torna-se índice relativo à burguesia ${ }^{\mathrm{I7}}$.

\section{Opacidade da operação intelectual}

A principal diferença entre as duas versões do roteiro é a inserção, na versão II, de novas personagens, como Oswald, Guilherme, Menotti e Raul Morais. Trata-se, logo se vê, de referências a intelectuais modernistas ${ }^{18}$. No caso de Oswald (de Andrade) e, principalmente, de (Mário) Raul (de) Morais (Andrade), trata-se de personagens com uma presença relevante na própria construção do enredo. É por intermédio de Raul Morais ("futurista de boa família") que Felisberto contrata Elza. Em troca, ele ganha o direito de testemunhar e escrever sobre o desenrolar dos acontecimentos. Dessa forma, parte das cenas diz respeito não ao seio da família de Felisberto, mas à casa de Raul Morais. É nesse espaço que Oswald faz sua principal aparição, momento em que sugere ao amigo a "expulsão" de quase todas as personagens, depurando a narrativa até deixar o essencial de São Paulo, "o japonês e a pretinha” (como se viu, empregados de Felisberto). Dessa forma ele termina por indicar que é na margem da narrativa que ocorre um lance essencial na existência da sociedade paulista, opondo a centralidade dos empregados à presença supérflua de Chopin num romance futurista. A tomada de consciência e a indicação cortante da posição do intelectual é mais problemática no caso de Raul Morais, dada sua ambivalência (testemunha/autor, "futurista de boa família”, crítico da situação/fiador de Elza). Há certo dilaceramento da posição do intelectual, ainda que Raul Morais também semeie suas sentenças, como se verá adiante.

É importante notar a esse respeito que a problemática do intelectual de esquerda havia entrado na ordem do dia com o golpe militar de $1964^{\text {I9 }}$. Embora não seja possível deslocar o campo cinematográfico dos demais, é conhecida a virada ocorrida no interior do Cinema Novo em filmes como O desafio (I964, direção de Paulo César Saraceni) e Terra em transe (I967, direção de Glauber Rocha) (XAVIER, 200I, p. 57-75). Em última instância, a versão II de Amar, verbo intransitivo dialoga com a crescente desconfiança em relação aos compromissos de classe que atravessam as formulações dos intelectuais de esquerda, como pode ser visto na personagem Raul Morais. Tornar opaca sua operação intelectual na narrativa é uma forma de refletir sobre o lugar social da personagem e também do autor. Diga-se de passagem, é interessante notar

I7 Celso Luft (2007) nota que a própria sintaxe de Três mulheres de três PPPês carrega indicações de classe.

I8 No roteiro Em memória de Helena, ocorre algo parecido. A personagem “tio Humberto” faz referência a

Humberto Mauro. Em Três mulheres de três PPPês há uma profusão de referências indiretas a intelectuais, sendo o "mestre Plínio" (Plínio Sussekind Rocha) a mais evidente. Em Cemitério, por meio de outro jogo de deslocamentos, personalidades são evocadas de forma mais explícita (Alberto Santos-Dumont, Ruy Barbosa, o próprio Salles Gomes).

I9 Carlos Guilherme Mota (20I4) e Marcos Napolitano (20I7) traçam um panorama mais completo sobre o tema. 
a confluência com a revisão realizada pelo próprio Mário de Andrade no contexto em que se deu seu contato com Salles Gomes, como fica indicado na "Elegia de abril" (ANDRADE, 2002, p. 207-2I8), publicada na revista Clima.

\section{Recuo prospectivo}

Trata-se de um paradoxo: o roteiro recua no tempo para sua crítica incidir no presente ${ }^{20}$. Vimos como algo semelhante ocorreu em Capitu, em que o Segundo Império mirava a atualidade. No entanto, há uma diferença significativa entre a analogia aí presente e a incidência de comentários sobre a atualidade numa história que se passa no passado. Afinal, as personagens de Amar, verbo intransitivo vaticinam sobre o futuro, isto é, o presente. A certa altura, por exemplo, alguém comenta que nos anos I970 os telefones continuariam a funcionar mal em São Paulo. O momento em que esse recuo prospectivo adquire contornos mais claros é quando Raul Morais, diante de uma estátua de um bandeirante, é instado por Felisberto a se pronunciar sobre como seria São Paulo no fim dos anos I960. Entre o passado e o futuro, a personagem hesita (“São Paulo será uma grande...") e sua hesitação é marcada com uma montagem paralela em que são apresentadas imagens "atuais", representando o trânsito, as favelas, os jornais Notícias Populares e O Estado de S. Paulo, o Jockey Clube e Roberto Campos. Preparados pelas imagens, chegamos à sentença da personagem: "uma grande... BOSTA". Em suma, da atualidade discreta projetada em Capitu, passa-se a uma articulação crítica mais explícita em Amar, verbo intransitivo.

A proximidade entre passado e presente é reforçada, como indicou Kinzo, pela identificação do autor com o intelectual-personagem. Essa identificação ganharia contornos mais claros na década de I970, tornando-se explícita em Cemitério, em que Paulo Emílio comparece como personagem a certa altura, terminando por arrebatar a narração. O mais decisivo nesse caso é o fato de essa identificação implicar necessariamente um exercício de rememoração. A tendência já aparece, como se viu, em textos do início dos anos I960, como "Variação de enterrado vivo", em que ficava indicada a importância do retorno involuntário de compulsões adquiridas através da experiência (os pesadelos sobre a fuga da prisão e sobre o horror do Estado Novo); nesse pequeno artigo, Salles Gomes aponta para a necessidade de recorrer às memórias para, no presente, explorar de forma "saudável" esses e outros horrores (GOMES, I986b). Talvez a contraparte da descrição maníaca seja a compulsão da memória involuntária ${ }^{21}$.

Contudo, ainda que o recuo prospectivo se desdobre em obras como Cemitério, há outras experiências no sentido de demarcar a atualidade da ficção de Salles Gomes nos anos I970. Talvez o caso mais claro seja a ênfase dada à temática da tortura. Ela emerge num pequeno conjunto de poesias produzido em I970, composto pelos poemas “Tortuto" (PI O282 - GOMES, I970a), jogo gráfico, no qual se fundem as palavras

20 Essas formulações dialogam com a noção de "estética do silêncio" (ADAMATTI, 20I9, p. 60-80).

2I Cemitério se articula a um processo amplo de rememoração em relação à experiência da prisão em I935-I937.

Esse movimento inclui o envio de cartas a antigos companheiros de cárcere. 
“Tutoia” e "tortura”, e "Paris I944 curvou-se ante São Paulo I970” (PI 028I - GOMES, I970b), em que há uma articulação entre o centro de tortura da rua Tutoia e a unidade da Gestapo na rua Lauriston. A ocorrência de uma referência mais direta nessas poesias não publicadas denota uma estratégia diversa de atualização: não mais um deslocamento no tempo, mas uma referência descontextualizada que retornaria de maneira muito aguda, como nota Roberto Schwarz (2007), em Três mulheres de três PPPês, e encontraria um depoimento em primeira pessoa em Cemitério ${ }^{22}$.

\section{Renovação do diagnóstico}

O que é entrevisto em Amar, verbo intransitivo e escancarado nos anos seguintes é o novo olhar lançado sobre o processo de modernização do país. Essa problemática enlaça boa parte da produção de Salles Gomes no início dos anos I970, evidenciando-se em sua tese de doutorado, publicada em I974. Uma das tensões básicas da tese reside no choque entre as tendências "espontâneas" de Humberto Mauro e sua tentativa de enquadramento por parte de Pedro Lima e Adhemar Gonzaga, redatores da revista Cinearte. Essa questão seria notada por Alfredo Bosi (2003), na já mencionada arguição de I972, que chama a atenção para o lugar do Modernismo e do próprio Salles Gomes na disputa em torno da modernidade. Em I974, num roteiro de conferência intitulado "P/ Curitiba” (PI 0455 - GOMES, I974), o crítico faz referência a essa questão, mas parece já manejar com clareza a observação de Bosi, traçando uma diferenciação do conservadorismo "caipira” de Mauro em relação à versão moderna e mesmo cosmopolita que caracteriza conservadores como Mário Behring, Adhemar Gonzaga e Pedro Lima, numa linhagem que se estende para o presente e abarca críticos associados ao Instituto Nacional de Cinema, como Flávio Tambellini, Antônio Moniz Vianna e Ely Azeredo.

O problema da modernização já fora delineado em Amar, verbo intransitivo. É importante retomar a passagem em que Raul Morais se pronuncia de maneira negativa ("BOSTA") sobre a possível realidade paulistana de I968-I969, lembrando do material fílmico heterogêneo articulado a essa sentença. Mais uma vez: trânsito, favelas, Notícias Populares, Jockey Clube, O Estado de S. Paulo, Roberto Campos. A articulação de elementos tradicionais da sociedade paulista (o Jockey Clube, o jornal O Estado de S. Paulo) a índices negativos da modernização (trânsito, favelas, Notícias Populares - violência) culmina com a referência a uma personagem-símbolo dessa conjugação entre arcaico e moderno, Roberto Campos ${ }^{23}$. Essa vinculação entre arcaico e moderno estaria no centro de Três mulheres de três PPPês (tortura, especulação imobiliária, Revolta Constitucionalista de I932/golpe militar de I964, televisão) e também nas pesquisas desenvolvidas por Salles Gomes junto ao Departamento de

22 É importante lembrar que a ameaça de demissão de Salles Gomes da USP, em I974, é provavelmente motivada pela sua referência à tortura numa conferência proferida no ano anterior.

23 Em I968, Salles Gomes publicou em A Gazeta o artigo “Roberto Campos em ritmo de aventura”, em que a referência irônica ao filme Roberto Carlos em ritmo de aventura (I968, direção de Roberto Farias) dava licença à crítica ao Instituto Nacional de Cinema e à atuação de Roberto Campos. 
Informação e Documentação Artísticas (Idart), entre I976 e I977 (PI o686 - GOMES, I977a; PI 0693 - GOMES, I977b; PI 0695 - GOMES, I977c; e PI 0696 - GOMES, I977d).

$\mathrm{O}$ ajuste de diagnóstico relaciona-se a um âmbito mais amplo quando lembramos do impacto causado por Macunaíma em Salles Gomes, conforme fica indicado no "Roteiro p/ Unesco". Vimos que essa reflexão foi construída em paralelo com a elaboração de Amar, verbo intransitivo. Ora, é importante lembrar que o filme de Joaquim Pedro toma distância do romance de Mário de Andrade ao articular de forma desencantada as personagens com o mundo das máquinas, pano de fundo para uma nova tentativa de abordar a realidade brasileira numa definição mais ajustada à experiência presente no espaço urbano (XAVIER, 20I2, p. 235-269).

\section{Dessolidarização}

A dessolidarização com a própria classe por parte de Salles Gomes já foi indicada por Carlos Augusto Calil (2007a; 2007b) e Roberto Schwarz (2008, p. I50-I75). Em Amar, verbo intransitivo, esse aspecto é evidenciado pelo recuo proporcionado pela inserção da personagem Raul Morais, na versão II, mas também pelo emprego de um vocabulário chulo ("BOSTA"). O contraste entre a seriedade e o ridículo das situações, referido por Schwarz (2008, p. I50-I75) a respeito de Três mulheres de três PPPês, ocorre em diversas ocasiões nos roteiros de I968-I969. A certa altura, por exemplo, um frequentador do bordel onde se encontra Felisberto lança a fórmula "Comme on dit à Itapetininga, bode velho é velho mas ainda é bode”, em que a conjugação da língua francesa com o dito e sua localização (Itapetininga) marca o disparate ${ }^{24}$. Em outra ocasião, Felisberto confunde um debate sobre a introdução do zebu com uma conversa sobre Camões, cujo retrato enfeita sua casa.

O deboche, portanto, preside uma atitude de incorporação livre do material social e literário à disposição do roteirista. É assim, por exemplo, que alguns temas presentes na obra de Mário de Andrade são retomados por Salles Gomes, mas têm seu sentido deslocado. É o que ocorre, por exemplo, com o tema das "específicas doenças paulistas”, citado em Remate de Males (ANDRADE, 20I3b, p. 332) em época próxima a Amar, verbo intransitivo, em que se fala da "faringite crônica de oitocentos mil paulistanos" (ANDRADE, 20I3a, p. 75). Ora, no roteiro essas formulações deslizam numa dupla construção, sempre associada à personagem Oswald, que passa da referência à "tosse especificamente paulista” à “burrice paulista específica”. A fórmula indica de maneira direta, portanto, uma dessolidarização que se constrói de maneira mais ou menos sutil em outras passagens. A expressão "burrice paulista específica" retornaria em outro material produzido na mesma época, o já mencionado roteiro "Possibilidade de um filme de longa-metragem em torno do cinema paulista de 1934 a I949" (PI oI73 e PI 06I4 - GOMES, s. d.; s. d.); ao falar sobre o desprezo da elite local pelo cinema dessa época, Salles Gomes menciona que ele era objeto de indiferença não apenas da "inteligência", mas também da "burrice paulista".

24 Em Cemitério (GOMES, 2007, p. 42), Ruy Barbosa afirma, a respeito de uma pintura que vê na Europa, que

"On dirait Jequié", em que a rima reforça a derrisão. 


\section{Batismo do corno, crisma da burguesia}

A dessolidarização se aglutina em torno de um ponto central, que está no cerne de Amar, verbo intransitivo: as condições de reprodução material da elite paulista, mais especificamente, a herança. Daí decorre, na ficção de Salles Gomes, a função estrutural que adquire a obsessão burguesa com o controle da masculinidade e do matrimônio. A questão se tornaria estruturante em Três mulheres de três PPPês: na primeira novela, com a ocultação da paternidade; na segunda novela, no cuidado com que Polydoro trata seu casamento, realizando-o no Paraguai para limitar sua validade; na terceira novela, na recomposição da virgindade. Ora, é interessante notar, a propósito de Amar, verbo intransitivo, que o enredo é pontilhado pelo problema da defesa de certa forma de masculinidade. Essa é prescrita numa conversa num "clube inglês", onde Felisberto e seus amigos dividem suas preocupações em relação à transição geracional, diante dos riscos representados a seus filhos pelas doenças venéreas, pelo anarquismo e pelo Modernismo. A construção de uma masculinidade "segura", isto é, heterossexual, ativa e consciente de seus compromissos de classe (em que a prostituição é um passatempo) é o que move Felisberto a contratar, como tantos outros membros da elite, os serviços de Elza.

Até aqui, portanto, sua família funciona como paradigma de classe. A certa altura, contudo, o pai sente-se corneado pelo filho, conforme nota Raul Morais ${ }^{25}$. Uma das mudanças mais notórias presentes nas duas versões do roteiro em relação ao romance de referência está justamente na rivalidade estabelecida entre pai e filho, causada pelo "excesso de masculinidade" deste, isto é, pelo rompimento do compromisso de classe, que põe em risco a distinção em relação a quem deve permanecer fora (Elza). Ao ser batizado explicitamente ("sentindo-se corneado" é a expressão utilizada na versão I), Felisberto dá nome à ameaça e confirma, a contrario, a conduta esperada dos membros de sua classe e de sua família. Resolvido o problema, seu filho Carlos termina no bordel frequentado pelo pai e tudo volta aos eixos; posteriormente, ele se reencontra com Elza, que já está inserida em outra família, zelando pela iniciação de outro jovem. Embora essa temática tenha uma articulação específica na construção de Amar, verbo intransitivo, o problema já se manifestava nos demais roteiros produzidos nos anos $1960^{26}$.

25 O que sugere outro sentido para o aparecimento da temática do zebu, retomada em mais de uma ocasião no roteiro, inclusive por parte de Raul Morais, que anota a certa altura a observação "Carlos e o zebu".

26 Com diferenças significativas, pois em Dina o problema se coloca nos quadros das tensões entre classes ao passo que em Amar ele se articulava ao problema da reprodução de uma classe particular. 


\section{Considerações finais}

Levando em conta o conjunto de características acima enumeradas, nota-se uma tentativa de alcançar um compromisso na elaboração das diferentes abordagens do romance de Mário de Andrade. Como nos demais roteiros de Salles Gomes, percebe-se a recusa de construir uma narrativa de ordem alegórica, tal como se processava em vários filmes da época ${ }^{27}$. Apesar dos deslocamentos temáticos e formais identificados, a construção do enredo e as sugestões de mise-en-scène que aparecem no roteiro preservam uma ordem realista, em que o sentido figurado parece concentrar-se na função indicial dos objetos. Estes sustentam uma atmosfera que penetra nos próprios mecanismos da narrativa, cujo ritmo é pontuado pela deriva descritiva. Tal mecanismo, no entanto, é atravessado pelo distanciamento estabelecido pela opacidade da operação intelectual envolvida na elaboração do roteiro e, mais que isso, pela antipatia do autor em relação ao objeto visado ${ }^{28}$.

Considerando o momento em que foi escrito, Amar, verbo intransitivo procura lidar com o silenciamento imposto pela ditadura (como no recurso ao recuo prospectivo) e também aos limites das posições assumidas nos anos anteriores (como ficou sugerido no contraponto com Dina). Importante ressaltar que a inervação do novo diagnóstico sobre a elite em torno da temática do corno e de toda a obsessão com as práticas corporais que daí decorrem não cabe na definição de "subjetivismo", expressão usada para caracterizar, por vezes de forma insuficiente, articulações intelectuais que destoam da posição político-cultural de alguma maneira associada ao âmbito nacional-popular. Retomando a última característica acima indicada, portanto, o roteiro tem o interesse de apontar para um debate que perpassou a recomposição do campo intelectual de esquerda na virada para os anos I970. Nesse sentido, a centralidade que se atribui ao problema do corno refere-se a uma especificação, ou melhor, a uma determinação objetiva que singulariza o diagnóstico acerca da elite paulista ${ }^{29}$. É o que estava em jogo na definição da sexualidade de Carlos. Assim, Amar, verbo intransitivo pode ser considerado um laboratório em que Salles Gomes experimentou um instrumental destinado a pôr em evidência a estreita e vigiada passagem do dois ao três da burguesia paulista, através de um dos aspectos mais arcaicos de sua reprodução.

27 O que estabelece restrições às comparações sugeridas acima entre o roteiro e alguns filmes, notadamente Macunaíma.

28 Essa talvez seja a principal diferença entre a proposta contida na versão II e a adaptação produzida anos depois com base no romance de Mário de Andrade, Lição de amor (I975, dir. Eduardo Escorel).

29 Num registro diverso, Lélia Gonzalez (I984) apontaria para a centralidade da definição de corno ou tio para analisar a branquitude. 
VICTOR SANTOS VIGNERON é doutorando em História Social na Universidade de São Paulo (USP). victor.jousselandiere@usp.br https://orcid.org/0000-0002-8I50-0386

\section{REFERÊNCIAS}

ADAMATTI, Margarida M. Crítica de cinema e repressão: estética e política no jornal alternativo Opinião. São Paulo: Alameda, 20I9.

A GRANDE feira. Direção: Roberto Pires. Drama. Brasil, I96I. (9I min.).

ANDRADE, Mário de. Aspectos da literatura brasileira. Belo Horizonte: Editora Itatiaia, 2002.

ANDRADE, Mário de. Amar, verbo intransitivo: idílio. Rio de Janeiro: Nova Fronteira, 2013a.

ANDRADE, Mário de. Poesias completas. Rio de Janeiro: Nova Fronteira, 2013b.

BAZIN, André. O que é o cinema?. São Paulo: Cosac Naify, 20I4.

BERNARDET, Jean-Claude. Brasil em tempo de cinema: ensaio sobre o cinema brasileiro de I958 a I966.

São Paulo: Companhia das Letras, 2007.

BOSI, Alfredo. Céu, inferno: ensaios de crítica literária e ideológica. São Paulo: Editora 34/Duas Cidades, 2003.

CALIL, Carlos Augusto. O caderno de Paulo Emílio. In: GOMES, Paulo Emílio Salles. Cemitério. São Paulo: Cosac Naify, 2007a, p. 97-זro.

CALIL, Carlos Augusto. Contra São Paulo In: GOMES, Paulo Emílio Salles. Três mulheres de três PPPês. São Paulo: Cosac Naify, 2007b, p. I79-I97.

CALIL, Carlos Augusto; MACHADO, Maria Teresa (org.). Paulo Emilio: um intelectual na linha de frente. Coletânea de textos de Paulo Emílio Salles Gomes. São Paulo: Brasiliense; Rio de Janeiro: Embrafilme, I986.

CAPITU. Direção: Paulo César Saraceni. Drama. Brasil, I968. (I05 min.).

CINEMATECA Brasileira. Arquivo Paulo Emílio Salles Gomes: Produção Intelectual (PI) oII5, oII6, oII6.oI, oII6.02, OII7, OII7.OI, OI73, 0207, O268, 0268. OI, O28I, 0282, 0296, 0455, 0486, 0486.0I, 0486.2, 0486.03, 05I6, 06I4, 0686, 0693, 0695, 0696 e 0840. Correspondência Ativa (CA) 0430, 0444 e 0585. Correspondência Passiva (CP) 1533 e I730.

DEUS e o diabo na terra do sol. Direção: Glauber Rocha. Drama. Brasil, I964. (I20 min.).

EISENSTEIN, Serguei. A forma do filme. Rio de Janeiro: Zahar, 2002.

GALVÃO, Maria Rita E. Crônica do cinema paulistano. São Paulo: Ática, I975.

GALVÃO, Maria Rita E. Burguesia e cinema: o caso Vera Cruz. Rio de Janeiro: Civilização Brasileira/Embrafilme, I98I.

GOMES, Paulo Emilio Salles. Manuscrito original da primeira versão de Dina do cavalo branco. São Paulo, I6 fev. I962a. II4 p. Manuscrito + 5 folhas manuscritas de acréscimo. Série: Produção Intelectual. Suporte: documentação escrita. Cinemateca Brasileira, Arquivo Paulo Emílio Salles Gomes. Acesso: BR CB PE/PI. oII6.

GOMES, Paulo Emilio Salles. Projeto de melodrama popular e moderno para o cinema 
ba-hiano. s.l., I962b. 79 p. Datilografado + I cópia carbono com anotações manuscritas. Série: Produção Intelectual. Suporte: documentação escrita. Cinemateca Brasileira, Arquivo Paulo Emílio Salles Gomes. Acesso: BR CB PE/PI. oII6. oI.

GOMES, Paulo Emilio Salles. [Projeto de melodrama popular e moderno para o cinema bahiano]. São Paulo, I96-a. 7I p. Xerográfico, datilografado e manuscrito. Série: Produção Intelectual. Suporte: documentação escrita. Tipo doc.: roteiro. Cinemateca Brasileira, Arquivo Paulo Emílio Salles Gomes. Acesso: BR CB PE/PI. oII6.o2.

GOMES, Paulo Emilio Salles. Sequência - Diálogo - Prólogo. São Paulo, I96-b. II5 p. Manuscrito. Anotação no alto da página: “Roteiro p/ David”. Série: Produção Intelectual. Suporte: documentação escrita. Cinemateca Brasileira, Arquivo Paulo Emílio Salles Gomes. Acesso: BR CB PE/PI. o268.

GOMES, Paulo Emilio Salles. Em Memória de Helena. São Paulo, I96-c. 76 p. Xerográfico e datilografado. Série: Produção Intelectual. Suporte: documentação escrita. Tipo doc.: roteiro. Cinemateca Brasileira, Arquivo Paulo Emílio Salles Gomes. Acesso: BR CB PE/PI. 0268.oI.

GOMES, Paulo Emilio Salles. Projeto de comédia dramática sofisticada para o cinema paulista. S.l, I96-d. 6 p. Manuscrito. Série: Produção Intelectual. Suporte: documentação escrita. Cinemateca Brasileira, Arquivo Paulo Emílio Salles Gomes. Acesso: BR CB PE/PI. 0207.

GOMES, Paulo Emilio Salles. [Carta para Michelle Sterling]. São Paulo, I963.04.03. I p. Datilografado, cópia xerográfica. Série: Correspondência. Suporte: documentação escrita. Tipo doc.: carta. Cinemateca Brasileira, Arquivo Paulo Emílio Salles Gomes. Acesso: BR CB PE/CA. 0430.

GOMES, Paulo Emílio Salles. [Carta para Yolanda Leite]. São Paulo, I965.0I.I2. I p. Datilografado, cópia xerográfica. Série: Correspondência. Suporte: documentação escrita. Tipo doc.: carta. Cinemateca Brasileira, Arquivo Paulo Emílio Salles Gomes. Acesso: BR CB PE/CA. 0444.

GOMES, Paulo Emilio Salles. O Universo Fílmico do Cangaço. São Paulo, I966a. Io p + cópia xerográfica com Iop. Datilografia. Série: Produção Intelectual. Suporte: documentação escrita. Tipo doc.: anotação para curso. Cinemateca Brasileira, Arquivo Paulo Emílio Salles Gomes. Acesso: BR CB PE/PI. 0486.

GOMES, Paulo Emilio Salles. O Universo Fílmico do Cangaço. São Paulo, I966b. I5 p + cópia xerográfica com I5p. Manuscrito. Série: Produção Intelectual. Suporte: documentação escrita. Tipo doc.: anotação para curso. Cinemateca Brasileira, Arquivo Paulo Emílio Salles Gomes. Acesso: BR CB PE/PI. 0486.oI. GOMES, Paulo Emilio Salles. Dioguinho. São Paulo, I966c. 55 p. Manuscrito. Resumo: análises detalhadas de filmes para uma compreensão total do universo do cangaço. Série: Produção Intelectual. Suporte: Documentação escrita. Tipo doc.: anotação para curso. Cinemateca Brasileira, Arquivo Paulo Emílio Salles Gomes. Acesso: BR CB PE/PI. 0486.02.

GOMES, Paulo Emilio Salles. [O Universo Fílmico do Cangaço]. São Paulo, I966d. 6I p. Datilografado. Resumo: análises detalhadas de filmes para uma compreensão total do universo do cangaço. Série: Produção Intelectual. Suporte: documentação escrita. Tipo doc.: anotação para curso. Cinemateca Brasileira, Arquivo Paulo Emílio Salles Gomes. Acesso: BR CB PE/PI. 0486.03.

GOMES, Paulo Emilio Salles. [Carta para Odete Lara]. São Paulo, 3 nov. I968a. 5 p. Manuscrito. O resumo apresentado por Paulo Emílio se transformou em roteiro. Cf. PE/PI. oII7. Resumo: envio de sinopse do roteiro baseado no romance Amar, verbo intransitivo, de Mário de Andrade. Série: Correspondência. Suporte: Documentação escrita. Tipo doc.: carta. Cinemateca Brasileira, Arquivo Paulo Emílio Salles Gomes. Acesso: BR CB PE/CA. 0585.

GOMES, Paulo Emilio Salles. Amar, verbo intransitivo. São Paulo, I969a. 44 p. Cópia xerográfica, datilografada. Resumo: adaptação cinematográfica do romance Amar, verbo intransitivo, de Mário de Andrade. Série: Produção intelectual. Suporte: documentação escrita. Cinemateca Brasileira, Arquivo Paulo Emílio Salles Gomes. Acesso: BR CB PE/PI. oII7. 
GOMES, Paulo Emilio Salles. Roteiro e diálogos p/ Amar, verbo intransitivo. São Paulo, I969b. II7 p. Manuscrito. Resumo: versão manuscrita do roteiro cinematográfico baseado no romance Amar, verbo intransitivo, de Mário de Andrade. Série: Produção intelectual. Suporte: documentação escrita. Cinemateca Brasileira, Arquivo Paulo Emílio Salles Gomes. Acesso: BR CB PE/PI. OII7.oI.

GOMES, Paulo Emilio Salles. Roteiro p/ Unesco. S.l., S.d. I2 p. Manuscrito. Resumo: o cinema brasileiro e sua relação com a literatura nacional. Série: Produção Intelectual. Suporte: Documentação escrita. Tipo doc.: conferência. Cinemateca Brasileira, Arquivo Paulo Emílio Salles Gomes. Acesso: BR CB PE/PI. 0516.

GOMES, Paulo Emilio Salles. Roteiro p/ mim. São Paulo, s.d. I2 p. Manuscrito e Datilografado. Em anexo, cópia datilografada, 4 páginas, mais I cópia carbono, 4 páginas. Resumo: roteiro cinematográfico que tematiza o universo dos empregados e o dos patrões. Série: Produção Intelectual. Suporte: Documentação escrita. Cinemateca Brasileira, Arquivo Paulo Emílio Salles Gomes. Acesso: BR CB PE/PI. OII5.

GOMES, Paulo Emilio Salles. Exposição sobre a participação das artes visuais na Semana de Arte Moderna. São Paulo, I97-. Io p. Manuscrito. Resumo: um balanço sobre o desenvolvimento desigual e combinado da literatura e das artes no Modernismo brasileiro. Série: Produção Intelectual. Suporte: Documentação escrita. Tipo doc.: anotação para curso. Cinemateca Brasileira, Arquivo Paulo Emílio Salles Gomes. Acesso: BR CB PE/PI. 0840.

GOMES, Paulo Emilio Salles. Tortuto. São Paulo, I970a. I p. Manuscrito. Referência à Rua Tutóia, onde funcionou uma unidade da OBAN, órgão de repressão na ditadura militar (I964-I984). Série: Produção Intelectual. Suporte: Documentação escrita. Cinemateca Brasileira, Arquivo Paulo Emílio Salles Gomes. Acesso: BR CB PE/PI. 0282.

GOMES, Paulo Emilio Salles. Paris I944 curvou-se ante São Paulo I970. São Paulo, I970b. I p. Manuscrito. Série: Produção Intelectual. Suporte: Documentação escrita. Ac Cinemateca Brasileira, Arquivo Paulo Emílio Salles Gomes. Acesso: BR CB PE/PI. 028I.

GOMES, Paulo Emilio Salles. O cinema brasileiro na década de trinta. São Paulo, I973.02.I6. 26 p. Manuscrito. Resumo: a sobrevivência do cinema brasileiro e suas principais personalidades na década de 3o. Série: Produção Intelectual. Suporte: Documentação. Cinemateca Brasileira, Arquivo Paulo Emílio Salles Gomes. Acesso: BR CB PE/PI. 0296.

GOMES, Paulo Emilio Salles. Possibilidade de um filme de longa-metragem em torno do cinema paulista de I934 a I949. São Paulo, s.d. 23 p. Manuscrito. Resumo: projeto de filme sobre o cinema paulista de I934 a I949. Série: Produção Intelectual. Suporte: documentação escrita. Cinemateca Brasileira, Arquivo Paulo Emílio Salles Gomes. Acesso: BR CB PE/PI. oI73.

GOMES, Paulo Emilio Salles. Possibilidade de um filme de longa-metragem em torno do cinema paulista de 1934 a I949. São Paulo, S.d. I5 p. Datilografado e Manuscrito. Resumo: roteiro para um filme sobre o cinema paulista de I934 a I949. Série: Produção Intelectual. Suporte: Documentação escrita. Tipo doc.: roteiro. Cinemateca Brasileira, Arquivo Paulo Emílio Salles Gomes. Acesso: BR CB PE/PI. o6I4.

GOMES, Paulo Emilio Salles. P/ Curitiba. Curitiba, I974. Io p. Manuscrito. Resumo: breve panorama das idéias cinematográficas brasileiras. Série: Produção Intelectual. Suporte: Documentação escrita. Tipo doc.: conferência. Cinemateca Brasileira, Arquivo Paulo Emílio Salles Gomes. Acesso: BR CB PE/PI. 0455 .

GOMES, Paulo Emilio Salles. Circo. São Paulo, I977a. I p. Manuscrito. O documento contém um envelope que indica a procedência do estudo: IDART. Resumo: análise de trabalho sobre o circo na cidade de São Paulo. Série: Produção Intelectual. Suporte: Documentação escrita. Tipo doc.: anotação. Cinemateca Brasileira, Arquivo Paulo Emílio Salles Gomes. Acesso: BR CB PE/PI. 0686. 
GOMES, Paulo Emilio Salles. Circo Arquitetura. São Paulo, I977b. 3 p. Manuscrito. O documento contém um envelope que indica a procedência do estudo: IDART. Resumo: análises de trabalhos sobre o circo e sua arquitetura, o metrô, a salão de convenções do Anhembi. Série: Produção Intelectual. Suporte: Documentação escrita. Tipo doc.: anotação. Cinemateca Brasileira, Arquivo Paulo Emílio Salles Gomes. Acesso: BR CB PE/PI. 0693.

GOMES, Paulo Emilio Salles. Arquitetura. São Paulo, I977c.03.00. II p. Manuscrito. Resumo: análise geral dos trabalhos sobre circo, arquitetura, metrô e o Anhembi. Série: Produção Intelectual. Suporte: Documentação escrita. Tipo doc.: anotação. Cinemateca Brasileira, Arquivo Paulo Emílio Salles Gomes. Acesso: BR CB PE/PI. 0695.

GOMES, Paulo Emilio Salles. Lanterna de fogo. São Paulo, I977d. I5 p. Manuscrito. Resumo: anotações para uma análise geral dos trabalhos realizados no IDART sobre circo, artes cênicas e teatro anarquista. Série: Produção Intelectual. Suporte: Documentação escrita. Tipo doc.: anotação. Cinemateca Brasileira, Arquivo Paulo Emílio Salles Gomes. Acesso: BR CB PE/PI. 0696.

GOMES, Paulo Emílio Salles. Humberto Mauro, Cataguases, Cinearte. São Paulo: Perspectiva/ Edusp, I974. (Estudos).

GOMES, Paulo Emílio Salles. Crítica de cinema no Suplemento Literário. Rio de Janeiro: Paz \& Terra, I98I.

GOMES, Paulo Emílio Salles. Vontade de crônica sobre o Circo Piolim solidariamente armado à Praça Marechal Deodoro. In: CALIL, Carlos Augusto; MACHADO, Maria Teresa (org.). Paulo Emilio: um intelectual na linha de frente. Coletânea de textos de Paulo Emílio Salles Gomes. São Paulo: Brasiliense; Rio de Janeiro: Embrafilme, I986a, p. 46-5I.

GOMES, Paulo Emílio Salles. Variação de enterrado vivo. In: CALIL, Carlos Augusto; MACHADO, Maria Teresa (org.). Paulo Emilio: um intelectual na linha de frente. Coletânea de textos de Paulo Emílio Salles Gomes. São Paulo: Brasiliense; Rio de Janeiro: Embrafilme, I986b, p. 229-23I.

GOMES, Paulo Emílio Salles. Cemitério, mais a peça teatral Destinos. São Paulo: Cosac Naify, 2007.

GOMES, Paulo Emílio Salles. Três mulheres de três PPPês. São Paulo: Companhia das Letras, 2015.

GOMES, Paulo Emílio Salles. Uma situação colonial?. São Paulo: Companhia das Letras, 2016.

GOMES, Paulo Emílio Salles; TELLES, Lygia Fagundes. Capitu. São Paulo: Cosac Naify, 2008.

GONZALEZ, Lélia. Racismo e sexismo na cultura brasileira. Ciências Sociais Hoje, I984, p. 223-244.

HEYEMANN, Luciana. Indivíduo, memória e resíduo histórico: uma reflexão sobre arquivos pessoais e o caso Filinto Müller. Estudos históricos, n. I9, I997, p. 4I-66.

KINZO, Carla M. Amar, verbo intransitivo: conjugações. Dissertação (Mestrado em Estudos Comparados de Literaturas de Língua Portuguesa). Universidade de São Paulo, São Paulo, 20I4.

LARA, Odete. [Carta para Paulo Emilio Salles Gomes]. Rio de Janeiro, I968.04.I5. I p. Datilografado. A sinopse (PE/CA. 0585) enviada por Paulo Emílio se transformou em roteiro cf. PE/ PI. oII7. Resumo: agradece o envio da sinopse de 'Amar, verbo intransitivo', de Mário de Andrade e informa estar extremamente atarefada com filmagens, mas insiste na relevância do trabalho e promete para julho a retomada da conversa em torno de um filme sobre o assunto. Série: Correspondência. Suporte: Documentação escrita. Tipo doc.: carta. Cinemateca Brasileira, Arquivo Paulo Emílio Salles Gomes. Acesso: BR CB PE/CP. I533.

LIÇÃO de amor. Direção: Eduardo Escorel. Drama. Brasil, I975. (85 min.).

LUFT, Celso. Da linguagem de Paulo Emílio. In: GOMES, Paulo Emílio Salles. Três mulheres de três PPPês. São Paulo: Cosac Naify, 2007.

MACUNAÍMA. Direção: Joaquim Pedro de Andrade. Comédia. Brasil, I969. (I08 min.).

MASSI, Augusto. Esquema para curso. In: GOMES, Paulo Emílio Salles; TELLES, Lygia Fagundes. Capitu. São Paulo: Cosac Naify, 2008, p. I85-196. 
MEMÓRIA de Helena. Direção: David Neves. Biografia. Drama. Brasil, I969. (80 min.).

MENDES, Adilson I. Trajetória de Paulo Emilio. Cotia: Ateliê Editorial, 2013.

MOTA, Carlos Guilherme. Ideologia da cultura brasileira (I933-I974): pontos de partida para uma revisão histórica. São Paulo: Editora 34, 20I4.

NAPOLITANO, Marcos. Coração civil: a vida cultural brasileira sob o regime militar (I964-I985). São Paulo: Intermeios/ PPGHS-USP, 2017.

O DESAFIO. Direção: Paulo César Saraceni. Drama. Brasil, I965. (94 min.).

PINTO, Pedro Plaza. Paulo Emilio e a emergência do Cinema Novo: débito, prudência e desajuste no diálogo com Glauber Rocha e David Neves. Tese (Doutorado em Ciências da Comunicação). Escola de Comunicações e Artes, Universidade de São Paulo, 2008.

PONTES, Heloisa. Destinos mistos: os críticos do Grupo Clima em São Paulo (I940-68). São Paulo: Companha das Letras, I998.

ROBERTO Carlos em ritmo de aventura. Direção: Roberto Farias. . Aventura. Musical. Brasil, I968. (97 min.). RODRIGUES, Lidiane Soares. A produção social do marxismo universitário em São Paulo: mestres, discípulos e um "seminário" (I958-I978). Tese (Doutorado em História Social). Universidade de São Paulo, São Paulo, 20II.

SARACENI, Paulo César. [Carta para Paulo Emilio Salles Gomes]. S.l., S.d. 2 p. Datilografado e xerográfico. Levando em consideração os filmes citados no documento, a correspondência pode ser datada entre os anos I964 a I967. Resumo: relato sobre a carreira do filme "O desafio" em alguns festivais na Europa e as ideias em torno da adaptação de "Dom Casmurro”. Série: Correspondência. Suporte: Documentação escrita. Tipo doc.: carta. Cinemateca Brasileira, Arquivo Paulo Emílio Salles Gomes. Acesso: BR CB PE/CP. I730.

SCHWARZ, Roberto. Forma excêntrica de luta de classes. Piauí, n. Io, 2007.

SCHWARZ, Roberto. Um romance paulista. In: TAVARES, Zulmira Ribeiro. O nome do bispo. São Paulo: Companhia das Letras, 2004, p. 228-23I.

SCHWARZ, Roberto. O pai de família e outros estudos. São Paulo: Companhia das Letras, 2008.

SOUZA, José Inacio de Melo. Paulo Emilio no Paraíso. Rio de Janeiro: Record, 2002.

TAVARES, Zulmira Ribeiro. Café pequeno. São Paulo: Companhia das Letras, I995.

TEM coca-cola no vatapá. Direção: Pedro Farkas e Rogério Corrêa. Documentário. Brasil, I975. (35 min.). TERRA em transe. Direção: Glauber Rocha. Drama. Brasil, I967. (I06 min.).

TRUE heart Susie. Direção: David Griffith. Drama. Romance. EUA, I9I9. (86 min.).

VIDAS secas. Direção: Nelson Pereira dos Santos. Drama. Brasil, I963. (I03 min.).

XAVIER, Ismail. Alegorias do subdesenvolvimento: Cinema Novo, Tropicalismo, Cinema Marginal. São Paulo: Cosac Naify, 2012.

XAVIER, Ismail. O cinema brasileiro moderno. São Paulo: Paz \& Terra, 200I.

ZANATTO, Rafael. Paulo Emílio e a cultura cinematográfica: crítica e história na formação do cinema brasileiro (I940-I977). Tese (Doutorado em História). Universidade Estadual Paulista, Assis, 2018.

ZANATTO, Rafael. Paulo Emílio e Os Filmes na Cidade (I966): a gênese da comédia musical. Rebeca, v. 9, 202I, p. 272-293. 